\title{
APLICAÇÃO DE SISTEMA DE INFORMAÇÃO GEOGRÁFICA NA ELABORAÇÃO DE MAPAS DE FERTILIDADE PARA A REGIÃO OESTE DA BAHIA
}

Marcelo Luiz Chicati ${ }^{1}$, Marcos Rafael Nanni ${ }^{2}$, Mônica Sacioto ${ }^{3}$, Carlos Antonio da Silva Junior ${ }^{3}$, Anderson Antonio da Silva ${ }^{3}$ e Franciele Romagnoli ${ }^{3}$

${ }^{1}$ Universidade Estadual de Maringá-UEM, Departamento de Engenharia Agrícola, Campus do Arenito. Rodovia PR 482, Km 45, CEP: 87820-000, Cidade Gaúcha, PR.

E-mail:mlchiati@hotmail.com

${ }^{2}$ Universidade Estadual de Maringá-UEM, Departamento de Agronomia, Avenida Colombo, 5790, Jardim Universitário, CEP: 87020-900, Maringá, PR.

${ }^{3}$ Universidade Estadual de Maringá-UEM, Pós-Graduação em Agronomia, Avenida

Colombo, 5790, Jardim Universitário, CEP: 87020-900, Maringá, PR

Recebido em: 03/01/2014 - Aprovado em: 04/04/2014 - Publicado em: 12/04/2014

\section{RESUMO}

A agricultura vem se aprimorando e passando por uma revolução das técnicas em manejo e as altas tecnologias, proporcionado uma alta taxa de fluxo de informações, esta revolução vem se acentuando pela utilização e a disponibilidade de novos avanços nas áreas da tecnologia integrante destas tecnologias os mapas de fertilidade foram possíveis pelo aprimoramento e disponibilização de softwares capazes de gerenciar, analisar e transformar estas informações em mapas temáticos, o mapa torna possível a visualização das porções do elemento analisado, podendo ser a porcentagem da areia, do silte, da argila, do teor de Cálcio, teor de Fósforo, do teor de Manganês, teor de Potássio, teor de Enxofre, da Matéria Orgânica e da CTC, as análises relacionadas a este trabalho se originaram na fazenda Guarani no lote "Lucia" no oeste baiano, um lote com 500 ha. onde foram efetuadas 171 amostras de solos com uma profundidade de 0 a 20 centímetros para gerar mapas de fertilidade da área.

PALAVRAS-CHAVE: Agricultura de Precisão, mapeamento, SIG.

\section{APPLICATION OF GEOGRAPHIC INFORMATION SYSTEM IN THE PREPARATION OF FERTILITY MAPS FOR THE WESTERN REGION OF BAHIA}

\begin{abstract}
Agriculture has been improving and going through a revolution in the technical management and high technology, providing a high rate of information flow, this revolution has been increasing the use and availability of new advances in technology these integral technologies maps of fertility were made possible by the improvement and availability of software able to manage, analyze and transform this information into thematic maps, the map makes it possible to view portions of the analyzed element, being the percentage of sand, silt, clay, content of calcium ,
\end{abstract}


phosphorus content, the content of manganese, potassium content, sulfur content, the organic matter and CEC, analyzes related to this work originated on the farm Guarani in " Lucia " lot in western Bahia, a batch of 500 ha. Where 171 soil samples with a depth of 0 to $20 \mathrm{~cm}$ to generate fertility maps of the area were made .

KEYWORDS: Precision Farming, GIS, mapping.

\section{INTRODUÇÃO}

A agricultura vem se tornando uma prática cada vez mais competitiva e organizada. Com a globalização de informações e os produtos se tornando importantes e valorizados commodities, os médios e grandes produtores estão se aprimorando e deixando para trás a velha imagem do agricultor sem conhecimento e se tornando empresário agrícola, com investimentos cada vez maiores em novas tecnologias e mão-de-obra especializada capaz de proporcionar uma nova visão e entendimento a pratica da agricultura moderna.

A agricultura tradicional por muitos anos ou por séculos vem caminhando a passos curtos com uma sucessão de erros e acertos, gerando um banco de dados apenas na memória do agricultor tornando o manejo da cultura uma tarefa desgastante, sem o apoio de novas tecnologias. Novas tecnologias como a aquisição de dados georreferenciadas, disponibilizaram uma importante ferramenta aliada ao produtor, dando apoio às tomadas de decisões com elevada precisão e histórico da área, disponibilizando comparações com medidas anteriores.

A Agricultura de Precisão (AP) favorece o agricultor e profissionais ligados à agricultura, em tomadas de decisões com dados específicos, histórico de produtividade, aplicação e quantificação, fertilizantes utilizados, corretivos, com base na variabilidade espacial dos nutrientes no solo (MOLIN, 2003). Essa AP provém de uma longa jornada de aprimoramento. Agricultores a um longo tempo buscam novos métodos para aperfeiçoar a sua propriedade como maximização da produtividade da cultura, a busca de melhoramento genético, novas tecnologias aplicadas em correção e adubação do solo, variando a taxa de insumo de acordo com as características dos solos e do desempenho da cultura (COELHO, 2002).

Com o intuito de aprimorar a distribuição de insumos agrícolas em pequenas porções de área, os fabricantes estão aprimorando seus maquinários, através de sensores e equipamentos acoplados aos maquinários. Os sistemas utilizados na agricultura de precisão são muitos, entre os principais o sistema de posicionamento global (GPS), sistemas de informações geográficas (SIG ou GIS), tecnologia de aplicação em taxa variável (VRT), monitoramento de áreas ("Crop Scouting"), sensoriamento remoto, monitores de colheita, amostradores de solo, aplicador de defensivos agrícolas autopropelidos, fotografias aéreas, estão entre as ferramentas com maior aceitação pelos agricultores no mercado (SCHOENAU \& GREER, 1996). Ferramentas aplicadas na agricultura de precisão podem ser utilizadas a formar um conjunto de informações ou podem ter sua utilização individualizada, tornando possível ao agricultor adaptar as ferramentas e as tecnologias de acordo com seu interesse e sua disponibilidade financeira (MAPA, 2013).

Um ciclo completo na agricultura de precisão tem além de determinações de campo, o processamento de dados e a elaboração de mapas de prescrição ou atributos para a correção de rumos, por essas necessidades muitos softwares foram desenvolvidos por entidades públicas e privadas, até mesmo em conjuntos, possibilitando ao usuário o aproveitamento máximo dos dados obtidos na área (PIRES, 2004). O Sistema de Informação Geográfica (SIG) organiza as informações 
por camadas temáticas armazenado de forma independente cada uma de suas camadas, isto possibilita o trabalho de forma rápida e prática, permitindo ao operador relacionar informações entre as diferentes camadas existentes (KORTE, 2001).

Os mapas de fertilidade podem ser utilizados na avaliação das causas da variabilidade e consequentemente, devem ser analisados por serem eficazes na formulação de soluções para os fatores que se tornam limitantes. Parte da variabilidade demonstrada em mapas de fertilidade deve ser atribuída a fatores constantes, ou que variam pouco ao longo do tempo, enquanto outros fatores são transitórios, enquanto outros fatores transitórios variando sua quantidade e consequentemente sua importância ao gerar mapas (MANTOVANI, 2008).

Assim, este trabalho teve o intuito de planejar e elaborar mapas de fertilidade de um lote pertencente à fazenda Guarani, localizada no oeste baiano e, assim, demonstrar as possibilidades de aplicação das ferramentas SIG para apoio do planejamento agrícola.

\section{MATERIAL E MÉTODOS}

A Coleta de dados foi realizada no oeste da Bahia em um lote de 500 hectares pertencente à fazenda Guarani, em Roda Velha, distrito de São Desidério na rodovia BR-020 Km 604 com uma altitude média de 900 metros, latitude S 1247' 41" e longitude W 46 14'33". O clima da região de São Desidério é tropical com estação seca no inverno (Aw) segundo a classificação climática de Koppen-GEIGER (1928), temperatura média de $24{ }^{\circ} \mathrm{C}$, com uma média pluviométrica de $1700 \mathrm{~mm} / \mathrm{ano}$ distribuídos entre final de setembro até meados de maio.

As coletas de solo foram realizadas por um quadriciclo modelo Honda $4 \times 4$ equipado com um coletor de solo e um receptor de GPS. Para iniciar as coletas o equipamento circunda toda a área, para gerar um mapa do contorno da área. $O$ próprio software do conjunto tem a capacidade de subdividir a área em grids. Neste caso foi utilizado o grid com malha de 2.93 ha. O equipamento coletou amostras na profundidade de 0 a 0,2 metros. As amostras foram acondicionadas em sacos plásticos transparentes e identificadas com o número da amostra e dados como latitude e longitude, e enviado para o laboratório de análises de solo (SANTOS et al., 2005).

Para modelagem de dados o software Spring versão 5.2.2, disponibilizado gratuitamente pelo INPE (Instituto Nacional de Pesquisas Espaciais), foi utilizado para geração de um banco de dados da área. Uma carta de Barreiras com escala de 1:250.000 foi utilizada, disponível pelo site do IBGE, a folha com os dados SD.23-VB MIR 346.

Nas 171 amostras de solo foram realizadas as seguintes análises: Textura (areia, silte, argila); CTC (cmol.kg-1); Saturação de bases (V\%);H+Al (acidez de troca) (cmolc. $\mathrm{dm}^{-3}$ ); M.O. (Walkley-Black) (\%); pH(água 1:1) (pH); P (Mehlich I) (ppm); P (resina) (ppm); K (Mehlich I) (ppm); Ca (Mehlichl) (cmolc.dm ${ }^{-3}$ ); Mg (Mehlich I) $\left(\mathrm{cmolc} . \mathrm{dm}^{-3}\right) ; \mathrm{S}$ (Mehlich III) (ppm); Alumínio (\% de saturação Al) (cmol. $\left.\mathrm{kg}^{-1}\right)$; Alumínio trocável (KCL) (cmol. $\left.\mathrm{kg}^{-1}\right)$.

Estas amostras foram coletadas em camada de $0-20 \mathrm{~cm}$. Os resultados foram transferidos para uma planilha eletrônica gerando um total de 3591 registros. No programa Spring foi criado o banco de dados para identificar e armazenar todos os dados gerados pela manipulação das imagens no programa. Após o registro da carta 
planialtimétricas disponível, o programa foi utilizado para manipular os dados. Foi criado um plano de informações para cada um dos atributos e foram armazenados os dados matriciais na categoria Atributos.

A criação de grade triangular foi feita em cada plano de informação. Com a grade triangular foi criada a grade retangular em cada plano de informação. Com a grade retangular pronta, faz-se 0 fatiamento. $O$ fatiamento proporcionou a classificação para cada intervalo de valores definidos por meio de tabelas da EMBRAPA para a região do cerrado brasileiro, sendo associadas cada intervalo a uma única cor. Assim, foi possível gerar mapas de cores indicativas de nível de teor dos elementos para todos os atributos analisados em laboratório.

\section{RESULTADOS E DISCUSSÃO}

No mapa de AREIA (\%) foi utilizada apenas uma classificação indicativa da amplitude dividida pelas quatro classes. Os valores do mapa AREIA (\%) (Figura 1) variaram de $50 \%$ até $70 \%$, a classe de 50 até $55 \%$ foi atribuída a cor verde escuro, pois dentro das condições esta é a mais favorável seguindo pela verde claro na faixa de 55.1 até $60 \%$, o amarelo ficou atribuído a classe de 60.1 até $65 \%$, o alaranjado ficou com a faixa de teor 65.1 até $70 \%$ sendo que esta é a menos desejada para solos agrícolas.

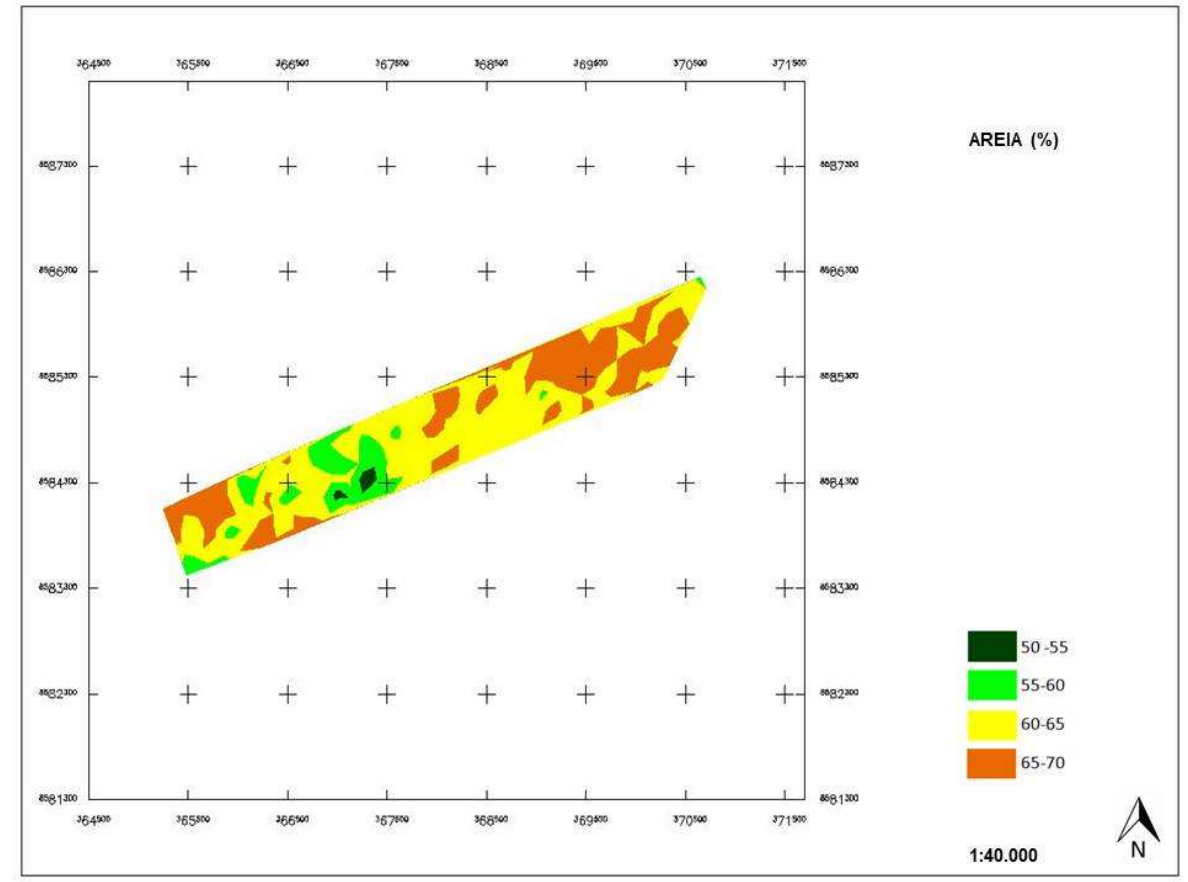

FIGURA 1. Mapa de distribuição de Areia (\%).

O mapa ARGILA (\%) (Figura 2) ficou estruturado com os seguintes valores: de 27 a $32 \%$ sendo a cor alaranjada, para baixo teor de argila; 32.1 até $37 \%$ ficou com a cor amarelo para médio teor de argila; de 37.1 até $42 \%$ ficou com a cor verde claro para bom teor de argila; e de 42.1 até $47 \%$ ficou com a cor verde escuro para ótimo teor de argila. 


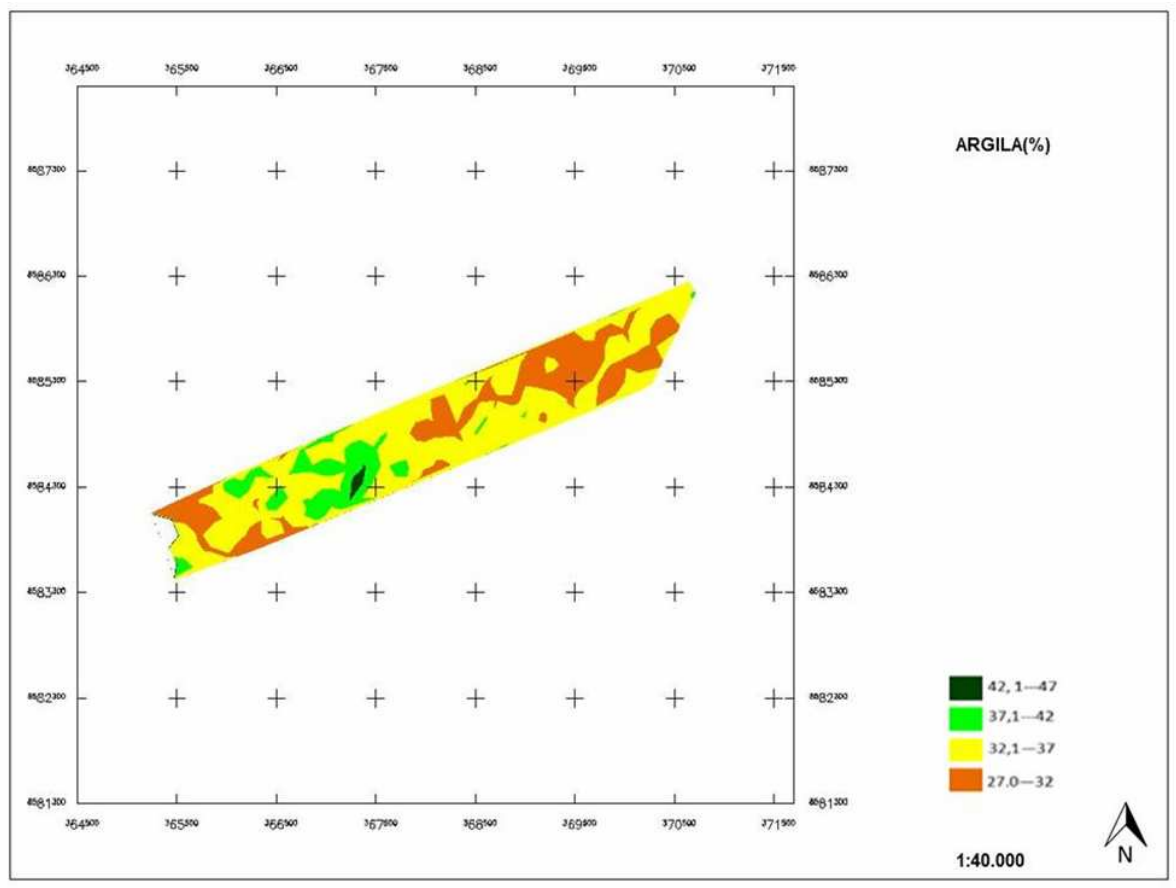

FIGURA 2. Mapa de distribuição de Argila (\%).

O mapa de SILTE (\%) (Figura 3) apresentou uma faixa de 1.20 até 7.60 e ficou dividido entre as seguintes classes: 1 até $2.5 \%$ alaranjado, 2.51 até $4 \%$ amarelo, 4.1 até $5.5 \%$ verde claro e de 5.51 até o maior número ficou com o verde claro.

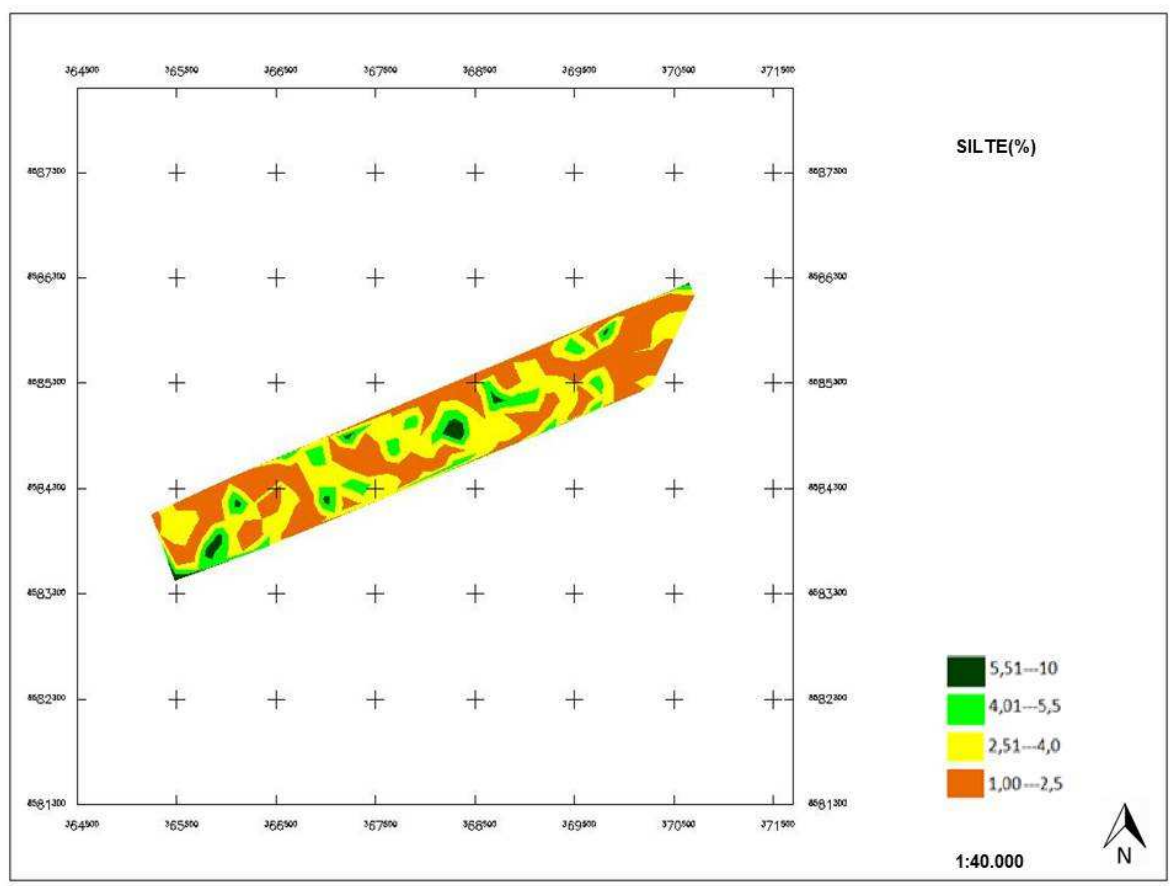

FIGURA 3. Mapa de distribuição de Argila (\%).

O mapa K (potássio) (Figura 4) foi baseado na tabela da EMBRAPA para cultivo de soja no cerrado e com suas classes 0 até 0.06 (ppm) ficou com a cor vermelha que representa um baixo teor de $\mathrm{K}$ para a cultura da soja extrair do solo, os valores de 0.07 até $0.13(\mathrm{ppm})$ ficou atribuída a cor amarela que indica um teor mediano e que precisa de incrementos para o cultivo da soja e as áreas que possuem um teor 
acima de 0.13 (ppm) ficou com a cor verde escuro que apresenta um ótimo teor de $\mathrm{K}$ para a extração no cultivo da soja.

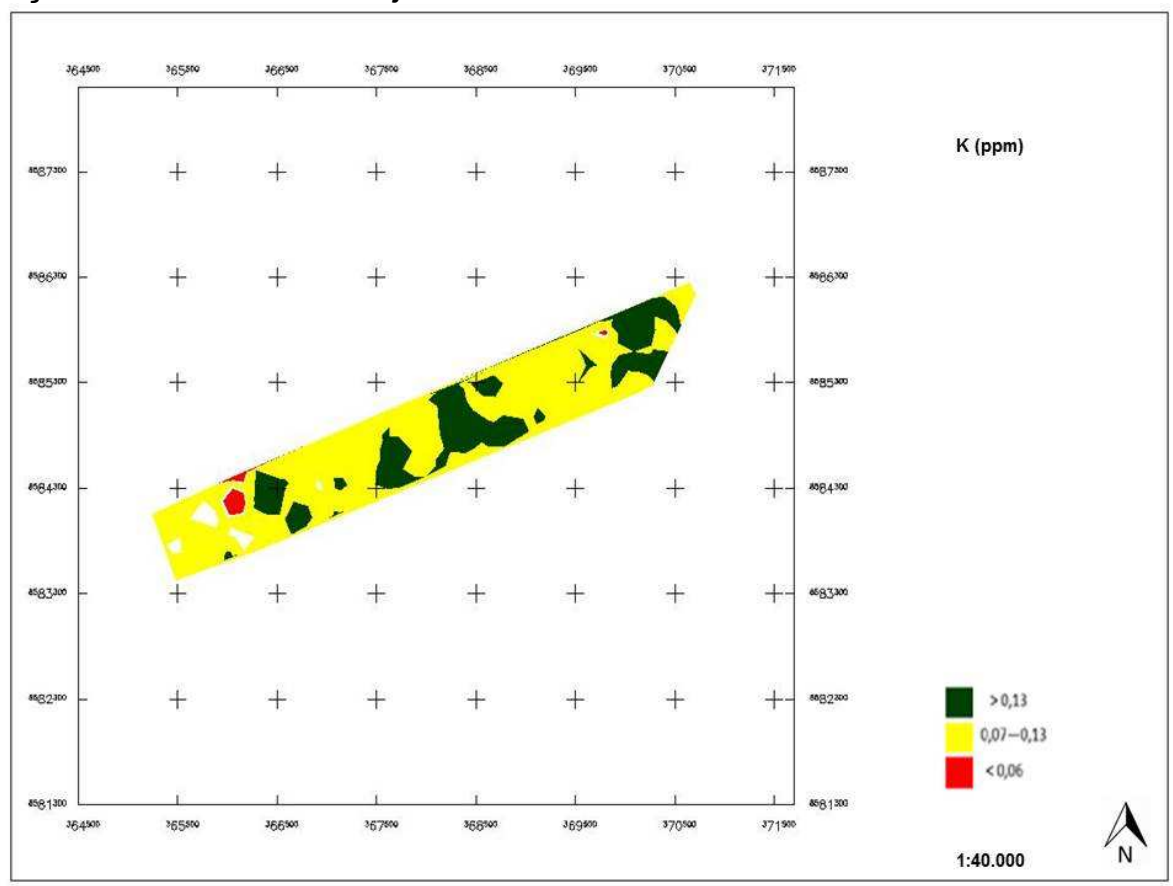

FIGURA 4. Mapa de distribuição de Potássio (ppm).

O mapa de ENXOFRE (S) (ppm) (Figura 5) foi representado pelos seguintes valores: 0 até 4.99 (ppm) pelo amarelo indicando um baixo teor de Enxofre; de 5.0 até $9.0(\mathrm{ppm})$ foi representada pela cor verde claro indicando um valor mediano para o Enxofre, e os valores acima de 9.1 foram representados pelo verde escuro representando um nível alto para este elemento no solo indicado para uma produção acima de $100 \%$.

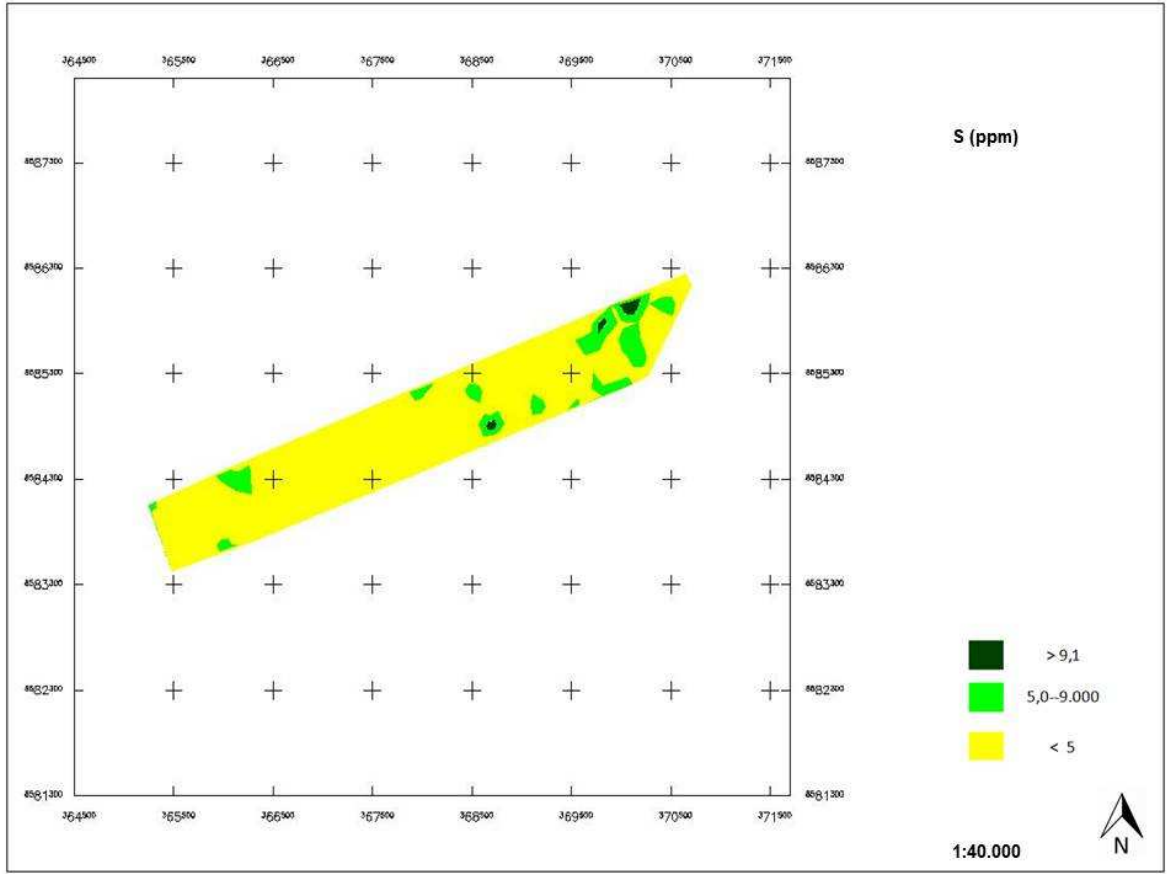

FIGURA 5. Mapa de distribuição de Enxofre (ppm). 
Com o mapa de FÓSFORO (P) (Figura 6) foi utilizado a tabela da EMBRAPA para cultivo de soja no cerrado e com teor de argila entra $15 \%$ a $35 \%$ na condição de sequeiro com os valores de 0 a $5.0 \mathrm{mg} . \mathrm{dm}-3(\mathrm{ppm})$ ficou com a cor vermelha representando um teor muito baixo, de 5.1 até $10.0(\mathrm{ppm})$ ficou com a cor alaranjada indicando um teor baixo para a cultura de soja, os valores de 10.1 ate $15(\mathrm{ppm})$ ficou representado pela cor amarela, indicando uma faixa média para a disponibilidade de P presente no solo, os valores de 15.1 até $20(\mathrm{ppm})$ é representado pela cor verde claro indicando uma teor adequado para $\mathrm{P}$ presente no solo e a cor verde escura representou a faixa que varia acima de $20(\mathrm{ppm})$ de P presente no solo.

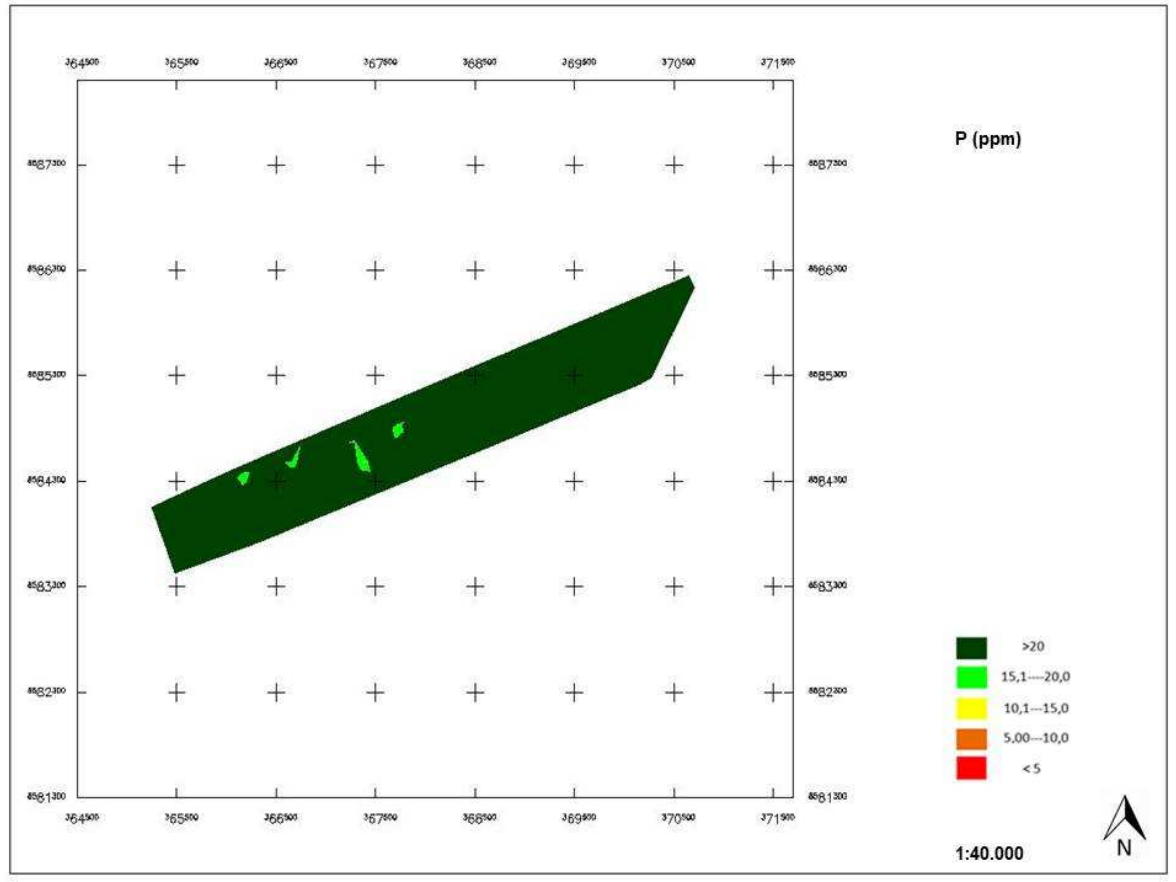

FIGURA 6. Mapa de distribuição de Fósforo (ppm).

O mapa de Magnésio (Mg) (Magnésio) (Figura 7) foi fatiado com os seguintes valores: 0 até $0.5\left(\mathrm{cmol}_{\mathrm{c}} \cdot \mathrm{dm}^{-3}\right)$ ficou com o amarelo representando um baixo teor de $\mathrm{Mg}$ no solo, de 0.5 até 2.0 fiou com o verde claro indicando um teor adequado, e para os valores maiores que 2.1 ficou com o verde escuro indicando um alto teor de Mg no solo. 


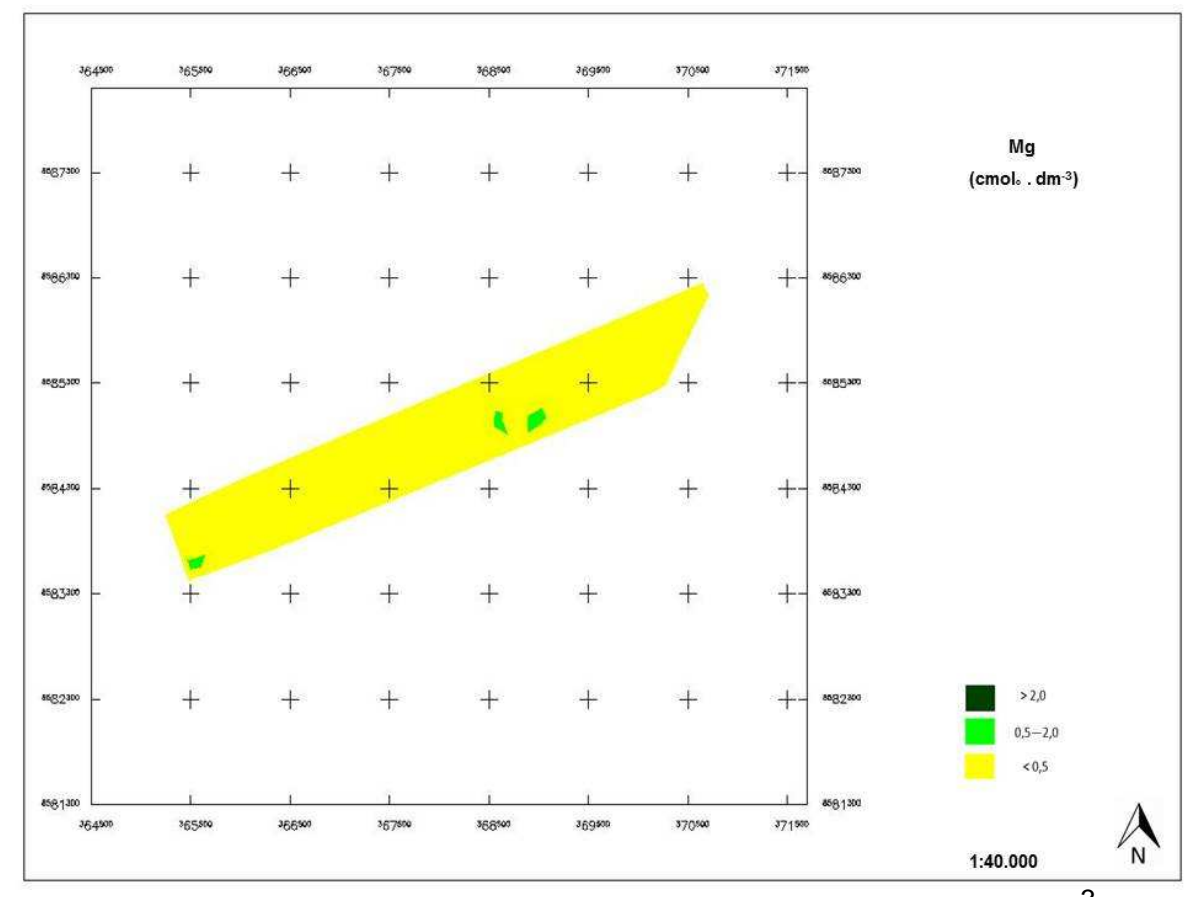

FIGURA 7. Mapa de distribuição de Magnésio $\left(\mathrm{cmol}_{\mathrm{c}} \cdot \mathrm{dm}^{-3}\right)$.

O mapa de Cálcio ( $\mathrm{Ca}$ ) (Figura 8) ficou dividido entre as seguintes classes, os valores de 0 até 1,5 (ppm) ficou representado pelo amarelo revelando um baixo teor do elemento presente no solo, os valores de 1.51 até 7.0 ficou representado pelo verde claro indicando um teor adequado de $\mathrm{Ca}$ no solo e os valores acima de 7.01 é representado pelo verde escuro representando um valor alto para o Cálcio exigida em altas produtividades no solo.

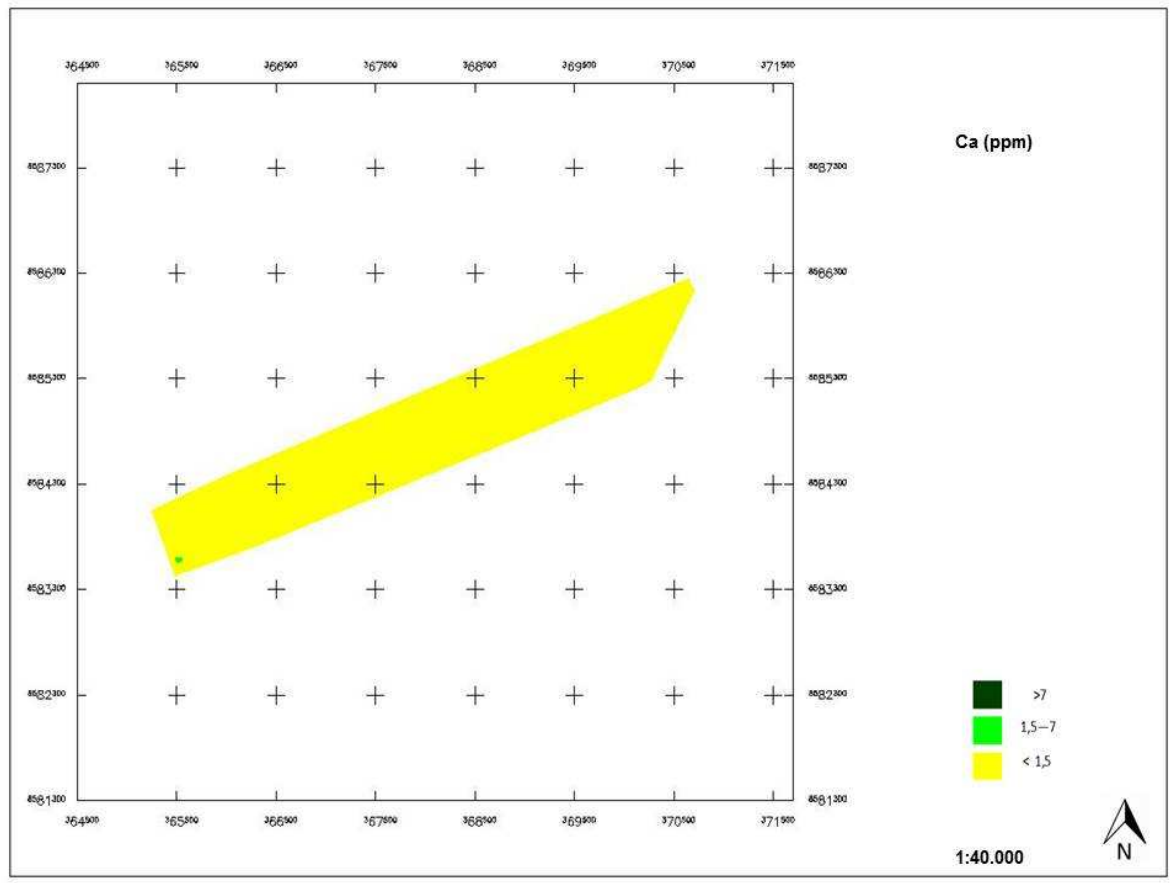

FIGURA 8. Mapa de distribuição de Cálcio (ppm).

O mapa de Matéria Orgânica (M.O.) (Figura 9) ficou representado pelos seguintes valores e cores: 0 até $0.70 \%$ pela cor vermelha, 0.71 até $2.00 \%$ ficou 
representada pela cor alaranjado, os valores de 2.01 até $4.00 \%$ foi representada pela cor amarela, os valores entre 4.01 até $7.00 \%$ foi representado pelo verde claro e os valores acima de $7.01 \%$ ficou com a cor verde escura .

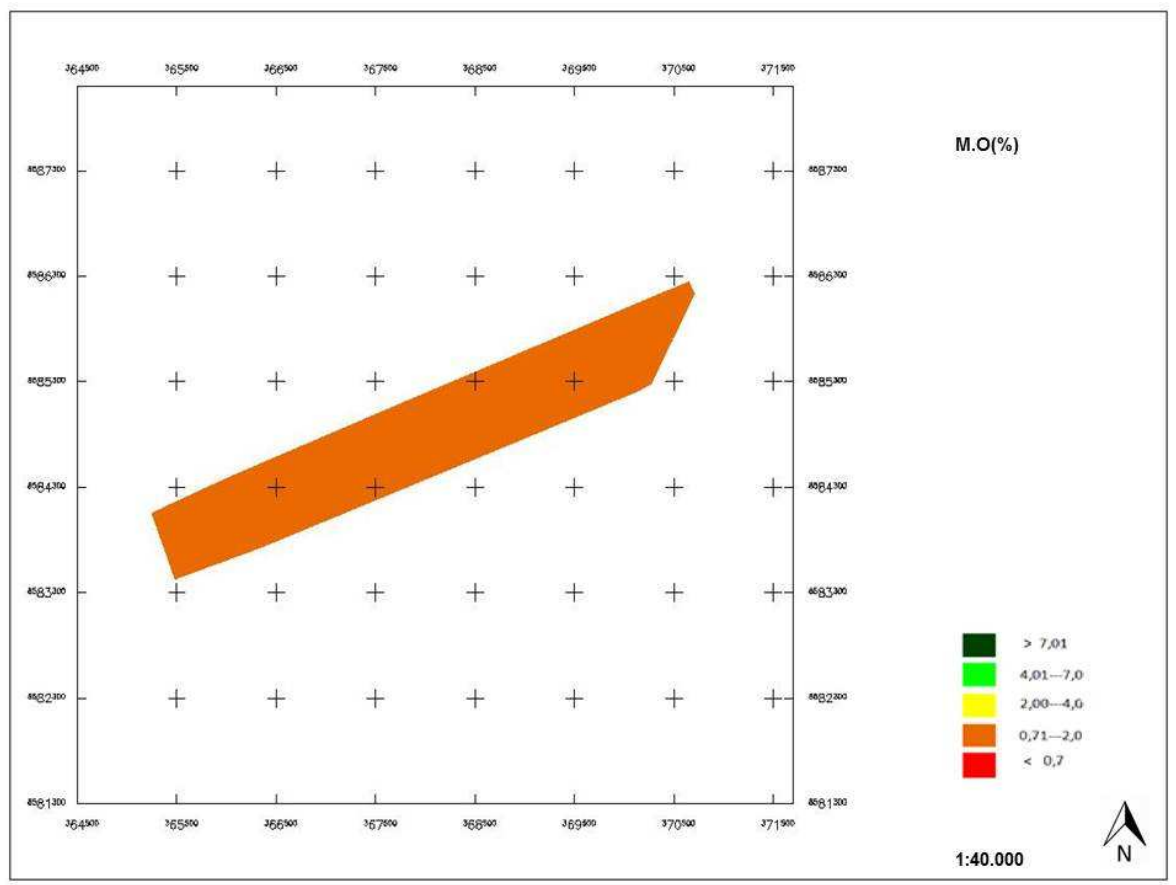

FIGURA 9. Mapa de distribuição de Matéria Orgânica (\%).

O mapa da CTC $\left(\mathrm{cmol}_{\mathrm{C}} \cdot \mathrm{dm}^{-3}\right)$ foi representado pelos seguintes valores e cores: os valores de 0 até $4.8\left(\mathrm{cmol}_{\mathrm{c}} \cdot \mathrm{dm}^{-3}\right)$ ficou representado pela cor alaranjada, os valores de 4.81 até 6.0 foi representada pela cor amarela, os valores de 6.1 até 9.0 ficou com a cor verde claro e os valores acima de 9.01 foi representado pela cor verde escuro.

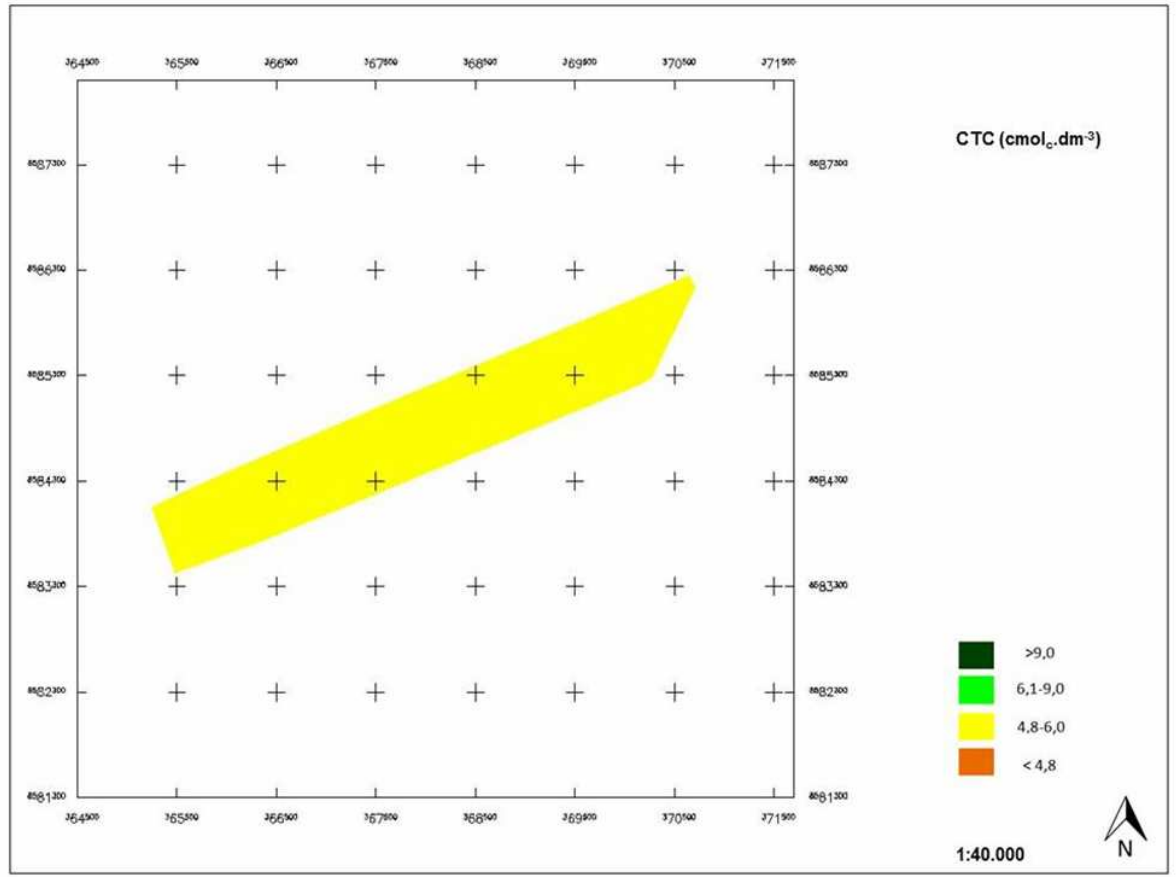

FIGURA 10. Mapa de distribuição de CTC $\left(\mathrm{cmol}_{\mathrm{C}} \cdot \mathrm{dm}^{-3}\right)$. 
A informação da posição geográfica de cada ponto coletada separadamente demonstrou que, de forma conjunta com as análises físicas e químicas de solo, é possível realizar uma predição espacial de atributos com clareza e eficiência, assim como apresentado por LAMPARELLI et al. (2001). Essas informações advindas dos diversos mapeamentos, aliadas às recomendações adequadas para o manejo do solo e culturas a serem implantadas também tem influência decisiva sobre o aproveitamento dos resultados obtidos nesse trabalho, como observa também PASSOS et al. (2011).

Os resultados apresentados também vêm corroborar o exposto por autores como OLIVEIRA et al. (2008), BARBIERI et al. (2008) e WEIRICH NETO et al. (2006) que afirmam ser esta técnica de mapeamento de atributos de solo uma excelente alternativa para a difusão da Agricultura de Precisão e, consequentemente melhor aproveitamento dos fertilizantes e corretivos agrícolas.

Fica evidente, desta forma, que a busca por economia e praticidade nos levantamentos de atributos de solos torna-se muitas vezes não representativa das reais características de campo, tal como expresso por NANNI et al. (2011).

\section{CONCLUSÕES}

O Sistema de Informação Geográfica (SIG) demonstrou-se eficaz na confecção de mapeamentos dos mais diversos atributos de solo para esta área de estudos. Sendo assim, pode-se considerar que o SIG tem potencial para ser empregado como mecanismo de tomada de decisões em diversas atividades de gerenciamento agrícola.

\section{REFERÊNCIAS}

BARBIERI, D. M.; MARQUES JUNIOR, J.; PEREIRA, G. T.. Variabilidade espacial de atributos químicos de um argissolo para aplicação de insumos à taxa variável em diferentes formas de relevo. Engenharia Agrícola. vol.28, n.4, p. 645-653, 2008.

COELHO, A. M. Agricultura de Precisão: Manejo da Variabilidade Espacial e Temporal dos Solos e das Culturas. In: Tópicos em Ciência do Solo, Volume III, SBCS, Viçosa, p 249-250, 2002.

KÖPPEN, W.; GEIGER, R. Klimate der Erde. Gotha: Verlag Justus Perthes. 1928. Wall-map.

KORTE, G. B. The GIS Book, How to Implement, manage, and asses the value of geographic information systems. 5aed., Santa Fe, OnWorld Press 2001, 387 p.

LAMPARELLI, R.A.C.; ROCHA, J.V.; BHORGUI, E. Geoprocessamento e agricultura de precisão - Fundamentos e Aplicações. Guaíba: Agropecuária, 2001. vol.1. 118 p.

MANTOVANI, E. C.; MATOSO, M. J. ; OLIVEIRA, A. C. ; AVELLAR, G. . Gestão de sistema de produção agrícola utilizando conceito de agricultura de precisão para a 
tomada de decisão. Revista Brasileira de Engenharia de Biossistemas, v. 1, p. 92-208, 2008.

MAPA, Agricultura de precisão. Ministério da Agricultura, Pecuária e Abastecimento Secretaria de Desenvolvimento Agropecuário e Cooperativismo. Brasília: Brasil. Ministério da Agricultura, Pecuária e Abastecimento. 2013. 36 p.

MOLIN, J.P. Agricultura de Precisão: situação atual e perspectivas. In: FANCELLI, A. L.; Piracicaba, p. 89-98, 2003.

NANNI, M. R.; POVH, F. P.; DEMATTÊ, J. A. M.; OLIVEIRA, R. B.; CHICATI, M. L.; CEZAR, E. Optimum size in grid soil sampling for variable rate application in sitespecific management. Scientia Agricola, v.68, n.3, p.386-392, 2011.

OLIVEIRA, R. B.; LIMA, J. S. S.; XAVIER, A. C.; PASSOS, R. R.; SILVA, S. A.; SILVA, A. F. Comparação entre métodos de amostragem do solo para recomendação de calagem e adubação do cafeeiro conilon. Engenharia Agrícola. v.28, n.1, p. 176186, 2008.

PASSOS, A. M. A.; REZENDE, P. M.; ALVARENGA, A. A.; BALIZA, D. B.; CARVALHO, E. R.; ALCÂNTARA, H. P. Yield per plant and other characteristics of soybean plants treated with kinetin and potassium nitrate. Ciência Agrotecnológica. vl.35, n.5, p.965-972, 2011.

PIRES,J. L. F. CUNHA, G. R. da; PASSINATO, A.; FRANÇA, S.; RAMBO. L. Discutindo agricultura de Precisão - aspectos gerais. Passo Fundo: Embrapa Trigo, 2004. 18p.

SANTOS, R.D. et. al. Manual de descrição e coleta de solos no campo, $5^{\text {a }}$ ed. Revista e ampliada Viçosa, Sociedade Brasileira de Ciências de Solo, 2005.

SCHOENAU, J; GREER, K. Field mapping of soil nutrient supply rates. Better Crops, Norcross, v. 80, n. 3, p. 12-13-17, 1996.

WEIRICH NETO, P. H.; SVERZUT, C. B.; SCHIMANDEIRO, A. Necessidade de fertilizante e calcário em área sob sistema plantio direto considerando variabilidade espacial. Revista Brasileira de Engenharia Agrícola e Ambiental. vol.10, n.2, p. 338-343, 2006. 